\title{
Application of PWI-SF for Screening High-Risk Group of Mental Health among College Students
}

\author{
Seung-Ah Jung1)
}

\begin{abstract}
The purpose of this study is to examine the psychometric properties of Psychosocial Well-Being IndexShort Form (PWI-SF) to identify students who are vulnerable to high-risk mental health. The results of the PWI-SF will help college students consider factors on how to adapt to college environment. Ultimately, the results of the study will determine the applicability of the said test to college students. The study administered both PWI-SF and the Korean version of Beck Depression Inventory (K-BDI-II) to randomly selected 1,787 college students in G-city. There were three aspects considered and performed in the analysis. First, the researcher calculated the internal consistency (Cronbach's a)of the normal college student's group and compared it with the reports of previous studies to assess the stability of the analysis. Second, exploratory and confirmatory factor analysis was conducted to check the applicability of the proposed four-factor structure on normal college students' group. Third, after examining both the distribution of K-BDI-II scores and the critical item, an appropriate cut-off score was proposed based on the screening situation of the high-risk group. Finally, the results of this study showed the usefulness and limitations of PWI-SF in screening the high-risk group of mental health.
\end{abstract}

Keywords: PWI-SF, College Students, Mental Health, High-risk Group, Screening

\section{Introduction: The Purpose of Study and its Objectives}

In an organization or a large group of community, it is imperative to properly screen members who are severely maladjusted or mentally vulnerable state. However, it is difficult to identify which method or procedure is appropriate considering the aspects of efficiency[1]. If the test is to be used for many individuals, the selected procedure should not be too complex. But these tests sometimes missed out those in vulnerable state. Therefore, the accuracy of the tools used should be considered to minimize or avoid omissions among screened individuals[2][3].

However, aspects of accuracy and efficiency conflict each other in the said tests. Less accurate tools will likely be used when focusing on efficiency. Hence, it is not easy to select a tool that compromise both accuracy and efficiency on screening individuals in large groups.

Received(November 20, 2019), Review Result(1st: December 24, 2019, 2nd: January 31, 2020), Accepted(April 25, 2020)

1) (Professor) 61452 Dept. Counseling Psychology, Chosun Univ. 309 Pilmun-Daero, Dong-Gu, Gwangju, Korea

email: jsa@chosun.ac.kr 
Diagnostic tools such as the revised Symptom Checklist-90 (SCL-90-R), Beck Depression Inventory (BDI), Beck Anxiety Inventory (BAI), and the Minnesota Multiphasic Personality Inventory (MMPI) are the standard tools in screening high-risk mental health individuals. These tools contain many questions because it explores a wide range of areas. For example, the MMPI-RF, which is the shortened form of MMPI-2, has 388 questions to be answered. These are the tools commonly used among large groups in an organization. Healthy people without clinical problems tend to feel uncomfortable when reading and responding to the questions of the said tools because most of the items suggest severe psychiatric symptoms. Most of the time, the respondents are repulsive, intimidated, and defensive. Therefore, even if they have relevant problems, they are likely to be omitted from the response process. On the other hand, this study will investigate whether the Psychosocial Well-Being Index-Short Form (PWI-SF) is an appropriate tool to regularly check the mental health status of the large group of college students and to detect their mental health status. The study considered PWI-SF because it may satisfy both the aspect of efficiency and accuracy issues of the tools mentioned above. The PWI-SF is not a tool for psychiatric diagnosis but to evaluate the vulnerability of mental health through the degree of daily stress experienced by regular people. The General Health Questionnaire (GHQ)[4], a widely used global tool, is the basis of PWI-SF. The questions are modified to fit the Korean culture. Initially, PWI-SF has 45 items. Later, the 18-item form[2] was produced.

Previous studies on PWI-SF focused on workers in specific occupational groups who are likely to be under stressful conditions. Few studies were conducted among college students, but the sample size was insufficient. Therefore, this study will use the PWI-SF to a large group of college students and test its efficiency and accuracy in detecting people with mental vulnerability.

\section{Method}

\subsection{Subjects}

A population of 18,497 college students from a university in $G$ metropolitan city received the online survey link through their mobile phones. Among the students, there were 1,787 respondents $(9.6 \%)$ who agreed to use their personal information and responses for the data analysis. More women (63.5\%) participated than men. The grade level distribution of the respondents are $19.4 \%, 24.0 \%, 26.8 \%$, and $29.8 \%$ respectively. 
The PWI-SF is an 18-item scale developed by Jang[5]. He modified the original scale of GHQ to fit the screening of Korean people for high-risk mental health group. GHQ is a screening measure that has already been widely used, based on the health psychological perspective that the level of stress experienced in everyday life is related to mental health. Therefore, PWI-SF aims to screen individual's mental health by simultaneously measuring the negative aspects (e.g. maladaptive functions) and the positive capabilities of a person to overcome stress. The PWI-SF consists of 18 items of which 11 are positive questions (e.g., feel energetic). Subjects respond using a four-point (0-1-2-3) scale. The author of PWI-SF identified four sub-factors (social role performance and self-confidence, depression, sleep disturbance and anxiety, general health and vitality) through factor analysis. He reported reliability coefficient (Cronbach's a) of .8802 with 6,997 workers[6]. In this study, the Cronbach's a was .918 .

The K-BDI-II, standardized by Kim et al.[7], is a tool for assessing the clinical level of depression. This scale consists of 21 items, and subjects should respond to questions on a four-point scale made of categorical options. Two-dimensional structure of general(g) and specific(s) factors (physical-emotional factors, cognitive factors) were identified in the standardization study with 1,022 adults[8]. The author of K-BDI-II reported an internal consistency coefficient (Cronbach's a) and the test-retest reliability of one-week interval of 89 and .90 respectively. The Cronbach's $a$ in this study was .922.

The study preformed a descriptive statistical analysis, reliability test, and exploratory factor analysis(EFA) using SPSS 23.0 while the confirmatory factor analysis(CFA) using AMOS 25.

\section{Results}

\subsection{Factor Structure and Psychometric Properties of PWI-SF}

There is a disagreement among researchers about the appropriate sample size for factor analysis, such as 100 is bad, 300 is good, and 1000 or more is excellent[9]. Combining the views of several researchers, Tak[10] suggested the standard criteria of the sample size in factor analysis for acquiring stable results which should be at least 200 or five times the measurement variables. According to these criteria, the number of cases of this study would be sufficient. Sphericity test identified the sampling adequacy for factor analysis. The Kaiser-Meyer-Olkin (KMO) measure was .942, which was excellent. It is assumed that there would be a correlation 
[Table 1] Results of CFA for Two and Four-factor Model

\begin{tabular}{ccccccccc}
\hline Index & $\mathrm{X} 2$ & $\mathrm{df}$ & $\mathrm{x} 2 / \mathrm{df}$ & $\mathrm{TLI}$ & $\mathrm{IFI}$ & $\mathrm{CFI}$ & $\mathrm{NFI}$ & \multirow{2}{*}{ RMSEA $\left(\mathrm{CI}^{*}\right)$} \\
\hline 2-factor model & 2018.586 & 134 & 15.064 & .893 & .906 & .906 & .900 & $.089(.085-.092)$ \\
\hline 4-factor model & 1321.696 & 129 & 10.246 & .930 & .941 & .941 & .935 & $.072(.068-.075)$ \\
\hline
\end{tabular}

$\mathrm{Cl}^{*}=$ confidence interval

between factors. Therefore, the principal axis factoring (PFA) was applied for factor extraction, while direct oblimin rotation (delta $=0$ ) was applied as rotation method. First, the factors were extracted based on the criteria of the eigen-value of 1 or higher without specifying the number of factors. The result of this procedure extracted two factors, and $61 \%$ of the total variance was explained. After reviewing the two factors extracted, the author found that the first factor was related to positive aspect such as sense of competence or happiness (e.g., "I feel that what I'm doing is going well overall"). The second factor was related to negative aspects associated with

[Table 2] 4-factor Structure of PWI-SF

\begin{tabular}{lcccc}
\hline \multicolumn{1}{c}{ items } & \multicolumn{3}{c}{ Factor } \\
\cline { 2 - 5 } 14. able to face up problems. & 1 & 2 & 3 & 5 \\
11. able to start something right away. & .899 & -.026 & -.133 & -.046 \\
10. satisfied with the method or procedure of what I have done. & .757 & -.004 & .042 & .044 \\
12. can enjoy normal daily life. & .727 & -.074 & .126 & -.031 \\
18. feel worth living my life. & .687 & .114 & .035 & -.028 \\
17. feel happy, all things considered. & .687 & .109 & .007 & -.002 \\
9. overall, feel that what I am doing now is going well. & .668 & .090 & .135 & .089 \\
8. like most people, I think I manage myself well. & .631 & -.148 & .204 & -.134 \\
4. can't sleep comfortably because of worries. & .462 & -.116 & .357 & -.105 \\
3. feel very tired and exhausted, so even eating is hard. & .066 & .729 & -.021 & -.087 \\
2. do not feel refreshed after sleeping. & .050 & .727 & -.082 & -.052 \\
6. feel full of energy. & -.024 & .554 & .187 & -.035 \\
5. feel my mind clear and clean. & .030 & .046 & .847 & .013 \\
1. feel very comfortable and health now. & .074 & .041 & .786 & -.032 \\
15. feel unhappy and depressed. & .202 & -.010 & .552 & -.101 \\
16. losing confidence in myself. & -.025 & .012 & .064 & -.808 \\
13. become restless or nasty. & .093 & -.041 & .007 & -.794 \\
7. at night, it gets disturbed or anxious. & -.077 & .214 & -.025 & -.518 \\
\hline
\end{tabular}

worry and confidence degradation (e.g., "I'm losing confidence in myself"). When applying the 
four-factor model, the third and fourth factors account for $69 \%$ of the total variance, although the said factors were below eigen-value of 1 . After examining the contents of items in these four factors, the author found that it was the same facture structures suggested by the original author.

The next step was to see if the fit of these four-factor structure could also be statistically verified. The CFA compared the goodness-of-fit of the derived two and four-factor model. The results (as shown in [Table 1]) showed that the two-factor model is not unacceptable, while the four-factor model is generally better for the main goodness-of-fit index

\subsection{Reliability, Psychometric Properties, and Cut-off Score.}

The PWI-SF mean score of 1,787 participants in this study was $16.86 \pm 10.00$ (range $0-50$ ), and the reliability coefficient (Cronbach's a) was .918. The classification ratio was $21.7 \%: 60.8 \%: 17.5 \%$ according to the classification criteria suggested by Jang (normal group: less than 8, potential
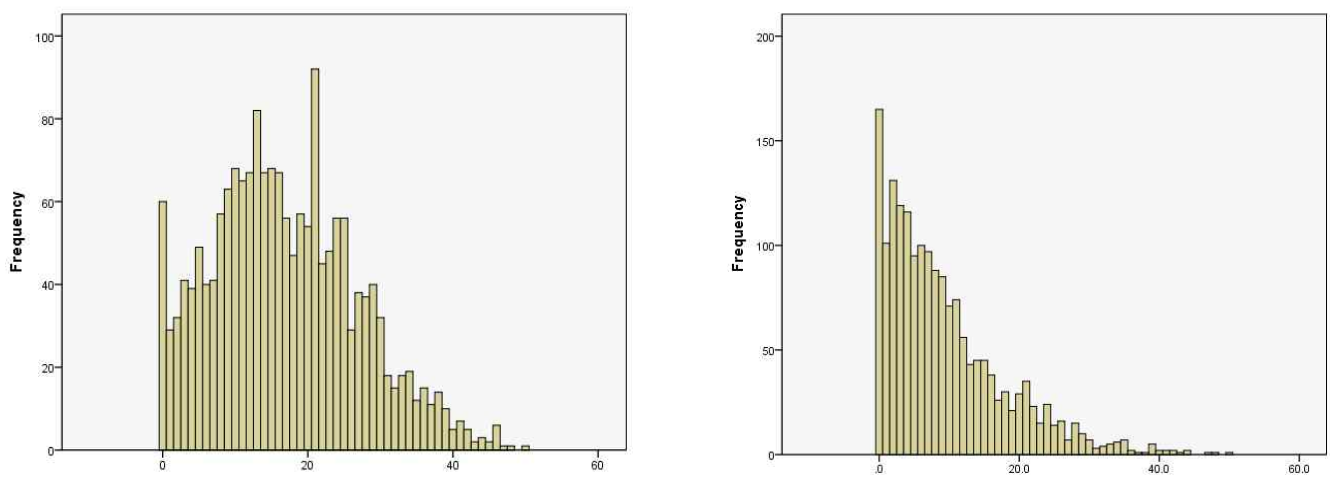

[Fig. 1] Distribution of Total Scores in PWI-SF(left) and K-BDI-II(right)

stress group: 9-26, high-risk group: more than 27)[5]. Compared with Jang's report on samples of workers across the country (mean $=19.67 \pm 7.57$, classification ratio $=5: 73: 22$, Cronbach's a $=.88$ ), the mean score in this study was lower, while the ratio of normal group and reliability index was higher. The overall distribution of the total score of PWI-SF showed a positively skewed pattern biased toward the lower scores, compared with the distribution of K-BDI-II as shown in [Fig. 1].

Then, it is necessary to examine how these psychometirc results, derived from college students, differ from those reported in previous studies. The PWI-SF tool have been used in many stress-related studies in Korea due to its capability of measuring the mental health status 
of individuals in various situations. Among 187 domestic papers extracted through online academic information service (RISS), 40 studies used PWI-SF, as shown in [Table 3]. The computed mean score or reliability index in this study was lower than the previous researches. In the current study, the proportion classified as normal group was higher and that of the high-risk group was lower, and the coefficient of internal consistency was relatively higher. In

[Table 3] Mean Score, Classification Ratio, Cronbach's a reported in Studies using PWI-SF

\begin{tabular}{|c|c|c|c|c|}
\hline studies & subject $(\mathrm{N})$ & $\begin{array}{c}\text { mean } \\
(\mathrm{PWI}-\mathrm{SF})\end{array}$ & $\begin{array}{l}\text { ration(\%) } \\
\mathrm{N}: \mathrm{L}: \mathrm{H}^{*}\end{array}$ & $a^{*}$ \\
\hline $\begin{array}{l}\text { Park S.Y. (2015) [11] } \\
\end{array}$ & Cancer survivors (168) & $16.50 \pm 8.49$ & 14.2: $74.4: 11.3$ & .70 \\
\hline Kim et al. (2017) [12] & Pneumothorax patients(101) & 39 & - & - \\
\hline Kim M.D. (2004) [13] & Farmers in JeJu(1086) & $20.27 \pm 9.509$ & 9.1: 69.1: 21.8 & .89 \\
\hline Yoo et al. (2011) [14] & Worker of Large Company (3228) & - & 4.7: 78.2: 17.1 & .61 \\
\hline Sung et al. (2017) [15] & Operating Room Nurses (269) & $32.44 \pm 5.79$ & 0: $13.0: 87.0$ & .68 \\
\hline Han et al. (2017) [16] & Dental practitioners (497) & - & 1.8: $63.8: 34.4$ & - \\
\hline Yoon et al. (2008) [17] & Nurses of University Hospital (810) & $33.10 \pm 4.29$ & 0: $13.0: 87.0$ & .706 \\
\hline Koh et al. (2005) [18] & Workers of Automobile factory (425) & $25.00 \pm 8.39$ & - & - \\
\hline Park et al. (2011) [19] & Nurses of University Hospital (450) & - & $10.2: 64.0: 25.8$ & .755 \\
\hline Sohn et al. (2010) [20] & Citizens of Seoul (1234) & - & 10.5:68.1:21:4 & .852 \\
\hline Lee et al. (2019) [21] & Famers in Kyong-Buk area (436) & - & 27.1: 60.3: 12.6 & - \\
\hline Sohn et al. (2019) [22] & Patients of Stroke (39) & $19.41 \pm 10.98$ & - & - \\
\hline Kim et al. (2004) [23] & Workers of Automobile factory (370) & - & 6.72:74.0: 19.3 & .940 \\
\hline Choi et al. (2009) [24] & Workers of Hospital (655) & $23.92 \pm 6.02$ & - & - \\
\hline Bae et al. (2018) [25] & Workers of Hospital (201) & $23.53 \pm 7.24$ & - & .716 \\
\hline Kim et al. (2009) [26] & Dental Technici & - & 2: $58: 40$ & .907 \\
\hline Kang B.W. (2009) [27] & hters (1100) & - & 5.2: $51.3: 42.3$ & .90 \\
\hline Jeong et al. (2015) [28] & Workers in Shipyard (7110) & - & 7.5:76.1:16.4 & - \\
\hline Cho et al. (2010) [29] & Clerical Public Officers (805) & $26.7 \pm 6.15$ & - & .778 \\
\hline Park et al. (2019) [30] & Breast Cancer Survivors (859) & $15.8 \pm 7.1$ & - & - \\
\hline Chae et al. (2016) [31] & $\operatorname{rss}(681)$ & $19.8 \pm 8.1$ & 80.2:19.8 & .926 \\
\hline Kim et al. (2006) [32] & Nurses of Unive & $21.7 \pm 6.9$ & 1.7: $73.2: 25.1$ & .892 \\
\hline Jeon et al. (2012) [33] & Female Adults ov & $17.48 \pm 8.01$ & - & .69 \\
\hline Kim et al. (2014) [34] & VTS Operators (84) & $21.20 \pm 6.79$ & 6.0:77.3:16.7 & .917 \\
\hline Kim J.Y. (2012) [35] & Preservice Child Care $\mathrm{T}$ & - & $.7: 77.2: 22.1$ & .82 \\
\hline Lee et al. (2012) [36] & Workers of Beauty Industry (813) & $30.76 \pm 6.96$ & - & - \\
\hline Kwon et al. (2019) [37] & Korean Medical Students (74) & $23.72 \pm 7.97$ & - & - \\
\hline Park et al. (2010) [38] & Employees of Research Institute (301) & $18.85 \pm 7.72$ & - & - \\
\hline Nam et al. (2010) [39] & Nurses of General Hospital (190) & $28.25 \pm 5.47$ & - & .911 \\
\hline Kim C.G. (2013) [40] & Mental Health Social Workers (154) & $18.78 \pm 8.26$ & - & .92 \\
\hline Ryou et al. (2009) [41] & Workers of Automobile Company (1470) & $22.26 \pm 7.62$ & $67.2: 30.4$ & .902 \\
\hline Kim Y.H. (2016) [42] & Adult Male and Female (620) & $20.23 \pm 9.48$ & 11.6: 62.9: 25.5 & .880 \\
\hline Cha et al. (2005) [43] & Industrial Workers (825) & - & 3.3: $74.3: 22.4$ & .879 \\
\hline Kim et al. (2006) [44] & Firefighters (167) & $22.4 \pm 7.1$ & $65.9: 34.1$ & .89 \\
\hline Shin et al. (2012) [45] & Residents Near Asbestos Mines (297) & $17.5 \pm 8.0$ & $86.5: 13.5$ & .91 \\
\hline Han et al. (2008) [46] & Rural Residents (1806) & $17.2 \pm 9.8$ & 20.0: 63.4: 16.6 & .874 \\
\hline Jo et al. (2016) [47] & Patients with periodontal disease (140) & $22.61 \pm 5.62$ & - & .866 \\
\hline
\end{tabular}


$\mathrm{N}$ : normal group, L: latent-risk group, H: high-risk group, *. Cronbach's a

addition, no study was conducted among general university students.

\section{Conclusions and Suggestions}

The PWI-SF was developed to assess potential risk factors threatening mental health through measuring stress level in everyday life. It has been applied to various normal groups but not to clinical groups. The GHQ itself, which was the basis of PWI-SF, is a tool to assess common underlying vulnerabilities in various mental disorders. Therefore, it can be assumed that PWI-SF also conceptually has one-dimensional structure. However, because the PWI-SF is not a tool that is validated by reinterpreting GHQ as it is, but a tool that adjusts the numbers and contents of items according to the context of Korea, it is necessary to verify the factor structure, reliability, and validity across various groups. Existing studies mainly targeted workers in stressful jobs. Therefore, the four factor structure reported by the author of PWI-SF should be verified if it is equally valid for college students' group. Using a scale without objective information or reference points about the sub-factorial structure of a scale limits the possibility of a detailed interpretation of the results.

The results of this study imply that PWI-SF is a useful tool for various groups in terms of efficiency and accuracy. The main implications and limitations of this study are as follows.

First, Even though PWI-SF is a self-reporting questionnaire with a small number of items, the four-factor structure suggested by the original author is stable when tested to general college student group. Conventionally, high-risk groups have been classified only by the total scores. But this study showed that the 4-factor structure is stable for general college students. Therefore, students who fell under this category need to take further evaluations based on the differences of their scores for each sub-factor.

Second, the internal consistency coefficient of PWI-SF measured in this study was quite high (.918), and the results of previous studies showed that the range of coefficient(.70-.90.) was stable enough across various workers groups. This suggests that PWI-SF is a tool that can be used not only for the various workers group but also for the college student group, though it has a small number of items.

Third, in this study, $17.5 \%$ of the students were classified as high-risk group when using 27 - poionts cut off score, which was proposed by original author. And the score for K-BDI-II 
corresponding to this same percentile was 16-17 point. But according to the criteria suggested by the authors of K-BDI-II, this score(16-17point) corresponds to the 'mild' depression level. The score of K-BDI-II range for the 'moderate' depression, which requires clinical attention was 20-28 points, and the cut-off points for 'severe' depressive state requiring urgent intervention was 29 points. Given that BDI is a standard tool with proven validity in clinical settings, we can discuss what would be the appropriate cut point for PWI-SF based on K-BDI-II scores. It is necessary to set the criteria higher in determining the high-risk groups using PWI-SF with normal group if we refer to the classification criteria in K-BDI-II. Specifically, considering the mean (9.39) and standard deviation (8.50) of K-BDI-II of the students participated in this study, and the score corresponding to the 'moderate' level of depression, which is 1.5 times the standard deviation(90 percentile), it seems appropriate to adopt the PWI-SF cut-off criteria of 30 points. This criteria is also useful and efficient when targeting large groups of general college students.

Fourth, although deviated from the normal distribution, the PWI-SF total score distribution in this study was closer to normal, compared with those of K-BDI-II conducted simultaneously. However, this pattern of PWI-SF distribution does not mean a negative result. Because most of the tests developed for screening high-risk groups measuring maladaptive properties usually shows a skewed distribution toward the lower side than the higher side. Thus, compared to K-BDI-II, this distribution may be an advantage. In other words, since PWI-SF was not developed for clinical diagnosis, it is more likely to detect students with mental health problems at a level slightly higher than normal when used for normal groups than tools for clinical diagnosis such as BDI.

Although this study has confirmed the usefulness of PWI-SF, it is necessary to mention the limitation of this study and the points to be supplemented in future studies. First, the response rate $(9.6 \%)$ in this study was too low, which makes it difficult to rule out the possibility that respondents are biased in groups with specific attributes. For example, the students of the study may have responded because they are free from mental health problems or on the contrary, have significant mental health problems with the intention of seeking help. Second, the cut-off point of 30 suggested was inferred indirectly. The usefulness of the screening tool depends on whether people with real problems or high vulnerabilities can be screened out without omission. This study indirectly deduced the cut-off point of PWI-SF by relying on K-BDI-II, but it needs to be verified by a more direct method in the future. For example, a longitudinal study must be conducted over a period time to confirm changes in PWI-SF score of groups exposed to apparent mental health problems. It is also suggested that the PWI-SF 


\section{References}

[1] Y. K. Lee, S. J. Oh, E. G. Ji, A study of the scale development for the social adaptability, Asia-pacific Journal of Psychology and Counseling, (2017), Vol.1, No.1, pp.23-28. DOI: 10.21742/apjpc.2017.1.1.04

[2] Y. J. Hur, The difference of self-efficacy and social well-being according to individual characteristics of college students, Asia-pacific Journal of Psychology and Counseling, (2018), Vol.2, No.2, pp.123-128. DOI: 10.21742/apjpc.2018.2.2.21

[3] S. E. Lee, Related factors of health behavior compliance among cardiac rehabilitation patients, Internaltional Journal on Consulting Psychology for Patients, (2018), Vol.2, No.2, pp.47-56. DOI: 10.21742/ijcpp.2018.2.2.08

[4] D. P. Goldberg, V.F. Hillier, A Scaled version of the General Health Questionnaire, Psychological Medicine, (1979), Vol.9, No.1, pp.139-145. DOI: 10.1017/s0033291700021644

[5] S. J. Chang, Standardization of collection and measurement for health data, Kyechukmunhwasa, Seoul, (2000), pp.121-159.

[6] S. J. Chang, S. B. Koh, M. G. Kang, B. S. Cha, J. K. Park, S. J. Hyun, J. H. Park, S. A. Kim, D. M, Kang, S. S. Jang, K. J. Lee, E. H. Ha, M. N. Ha, J. M. Woo, J. J. Cho, H. S. Kim, J. S. Park, Epidemiology of psychosocial distress in Korean employees, Journal of Preventive Medicine and Public Health, (2005). Vol.38, No.1, pp.25-37. UCI : G704-000038.2005.38.1.001

[7] S. U. Lim, E. H. Lee, S. T. Hwang, S. H. Hong, J. H. Kim, Psychometric properties of the Beck depression inventory-II in Korea, The 2014 Congress of Korean Clinical Psychological Association, (2014), October 16-17; Ilsan, Korea.

[8] S. U. Lim, E. H. Lee, S. T. Hwang, S. H. Hong, J. H. Kim, The Beck depression Inventory-second edition: psychometric properties in Korean adult populations, Korean Journal of Clinical Psychology, (2019), Vol.38, No.3, pp.300-307. DOI: 10.15842/kjcp.2019.38.3.003

[9] A. L. Comrey, H. B. Lee, A first course in factor analysis(2nd Ed.), Hilsdale, (1992)

[10] J. K. Tak, Psychological testing: An understanding of development and evaluation method(2nd Ed.), Seoul, Hakjisa, (2007)

[11] S. Y. Park, Physical activity, stress and physical health status of cancer survivors who undergone health examination : compared with non-cancer adults, Seoul University, Masters Thesis, (2015)

[12] D. H. Kim, H.. J. Shin, S. W. Kim, J. M. Hong, K. S. Lee, S. H. Lee, Psychological Problems of pneumothorax according to Resilience, Stress, and Post-Traumatic Stress, Psychiatry Investigation, (2017), Vol.14, No.6, pp.795-800. DOI: 10.4306/pi.2017.14.6.795

[13] M. D. Kim, Depression, Stress and Drinking Habit Including Alcohol Dependence in Jeju Rural Area, JOURNAL OF THE KOREAN NEUROPSYCHIATRIC ASSOCIATION, (2004), Vol.43, No.1, pp.29-39. UCI : G704-001050.2004.43.1.001 
[14] K. Y. Yu, K. J. Lee, K. B. Min, K. C. Park, S. K. Chae, J. B. Park, Association between job stress and mental health among workers in a large company, Journal of Korean Society of Occupational and Environmental Hygiene, (2011). Vol.21, No.3, pp.146-155. UCI : G704-000860.2011.21.3.006

[15] H. C. Sung, S. S. Jun, Coping, Stress and Turnover Intention in Operating Room Nurses Who Experienced Workplace Violence, Global Health and Nursing, (2017), Vol.7, No.2, pp.89-98. DOI: 10.35144/ghn.2017.7.2.89

[16] M. H. Han, K. H. Chung, The relationship between musculoskeletal pain and social-psychological factors among dental practitioners, Journal of Korean Academy of Oral Health, (2017), Vol,41, No.2, pp.137-143.

[17] H. S, Yoon, H. R. Kim, I. S. Kwon, Y. C. Cho, Type A behavior pattern and its association with stress, depression and fatigue in nurses, Korean Journal of Occupational Health Nursing, (2008), Vol.17, No.2. pp.180-190. UCI : G704-001949.2008.17.2.005

[18] D. H. Koh, S. S. Han, H. R. Kim, S. J. Chang, S. H. Choi, J. U. Won, J. H. Roh, Analysis of the Role of Social Support on Job Stress and Psychosocial Stress in Automobile Factory Workers Using Structural Equation Model, Annals of Occupational and Environmental Medicine, (2005), Vol.17, No.2, pp.79-84. UCI: G704-000627.2005.17.2.010

[19] S. K. Park, J. O. Kim, Y. C. Cho, Relationships Between Job Stress and Psychosocial Stress Among Nurses in a University Hospital, Journal of the Korean Academia-Industrial Cooperation Society, (2011), Vol.12, No.9, pp3887-3896. UCI: G704-001653.2011.12.9.025

[20] A. R. Sohn, T. K. Kim, E. J. Ryu, G. J. Oh, D. H. Ahn, Mental health and stress by socio-demographic characteristics among Seoul citizens, Korean Journal of Health Education and Promotion, (2010), Vol,27, No.1, pp.71-80. UCI: G704-000885.2010.27.1.010

[21] H. Lee, S. Y. Cho, J. S, Kim, S. Y. Yoon, B. I. Kim, J. M. An, K. B. Kim, Difference in health status of Korean farmers according to gender, Annals of Occupational and Environmental Medicine, (2019), Vol.31, No.1, pp.1-9. DOI: 10.1186/s40557-019-0287-7

[22] S. E. Sohn, G. W. Lee, N. H. Lee, H. N. Chae, M. J. Cheong, H. W. Kang, Y. S. Lyu, A study on the emotional characteristics of patients within one year of stroke using core seven emotions inventory-short form, The Korean Society of Oriental Neuropsychiatry, (2019), Vol.30, No.3. pp.165-175. DOI: 10.7231/jon.2019.30.3.165

[23] S. S. Kim, J. W. Hong, H. J. Han, The study on the relationship between job characteristics and psychosocial stress of workers in the automobile industry, The Journal of Traditional Korean Medicine, (2004), Vol.14, No.1, pp.1-16.

[24] S. Y. Choi, S. J. Im, Y. H. Lee, D. H. Park, The Effects of Hospital Worker's Job Stress and Work Posture Risk on the Muscular Skeletal Disease related Consciousness Symptom - With Emphasis on Path Analysis Model -, Journal of Korea Safety Management \& Science, (2009), Vol.11, No.4, pp.57-67. UCI: G704-001460.2009.11.4.017

[25] S. Y. Bae, S. H. Kim, AAnalysis of Convergent Influence of Self-Esteem, Fatigue and Psychosocial Stress on Depression among General Hospital Administrative Staff, Journal of Digital Convergence, (2018), Vol.16, No.9, pp.301-307.

[26] W. T. Kim, T. Y. Han, Assessment of Job stress and Psychosocial stress level using Psychosocial health measurement tool in dental technicians, Journal of Technologic Dentistry, (2009). Vol.31. No.3, pp.67-85. 
[27] B. W. Kang, A study on the relationship between Job Stress and Socio-Psychological stress of firefighter, The Korean Journal of Emergency Medical Services, (2009), Vol.13, No.1. pp.35-48. UCI: G704-SER000009858.2009.13.1.008

[28] H. W. Jeong, Y. C. Kim, A Study on Assessment of Stress at Work between White and Blue Collar Workers in Shipyard ,The Korean Society of Safety, (2015), Vol.30, No.5, pp.80-85. UCI: G704-000647.2015.30.5.019

[29] Y. C. Cho, I. S. Kwon, N. K. Bae, J. Y. Park, Effects on the Psychosocial Health Status of Job Stress and Job-related Characteristics among Clerical Public Officers using the Structural Equation Model, Journal of Korea Academia-Industrial cooperation Society, (2010), Vol.11. No.6, pp2169-2177. DOI: 10.5762/KAIS.2010.11.6.2169

[30] B. Y. Park, M. H. Lee, S. Y. Gong, E. S. Lee, Psychosocial health of disease-free breast cancer survivors compared with matched non-cancer controls, Cancer Reach and Treatment, (2019), Vol.51, No.1. pp.178-186. DOI: $10.4143 /$ crt.2017.585

[31] S. K. Chai, J. L. Kim, K. J. Lee, J. B. Park, Association between occupational stress and psycho-social stress among lawyers, Human Rights and Justice, (2016), Vol.458. pp.6-26.

[32] H. C. Kim, K. S. Kwon, D. H. Koh, J. H. Leem, S. G. Park, J. Y. Shin, Y. C. Lee, Y. K. Kim, The relationship between job stress and psychosocial stress among nurses at a university hospital, Annals of Occupational and Environmental Medicine, (2006), Vol.18, No.1, pp.25-34. DOI: 10.35371/kjoem.2006.18.1.25

[33] J. H. Jeon, S. H. Kim, Depression, stress and how they are related with health behaviors and metabolic syndrome among women over 40 years, Journal of The Korean Society of Maternal and Child Health, (2012), Vol.16, No.2, pp.263-273. DOI : 10.21896/jksmch.2012.16.2.263

[34] Y. S. Kim, Y. S. Park, S. H. Jo, A study on occupational stress of the VTS operators, Journal of Korean Navigation and Port Research, (2014). Vol.38, No.6, pp.615-621. DOI : 10.5394/KINPR.2014.38.6.615

[35] J. Y. Kim, A Study on the Psycho-social Health and Health Promoting Lifestyle of Preservice Child Care Teachers, Journal of Wellness, (2012), Vol.7, No.2, pp.165-179. UCI : G704-SER000002143.2012.7.2.024

[36] H. Y. Lee, S. Y. Choi, Effect of emotional labor, job and psychosocial stress, and fatigue of beauty industry workers on the perceived symptoms of musculoskeletal diseases, Journal of Korea Safety Management \& Science, (2012). Vol.14, No.4, pp.51-58. UCI : G704-001460.2012.14.4.024

[37] O. H. Kwon, J. H. Lee, Study on the relationship between type A behavior pattern and lifestyle and psychological characteristics of Korean medical students, Society of Preventive Korean Medicine, (2019), Vol.23, No.3. pp.71-82. DOI : 10.25153/spkom.2019.23.3.007

[38] C. J. Park, I. S. Kwon, Y. C. Cho, Relationship between psychosocial stress and coronary risk factors of employees in a research institute, Journal of Korea Academia-industrial Cooperation Society, (2010), Vol.11, No.1. pp.392-401. UCI : G704-001653.2010.11.1.034

[39] W. Nam, J. W. Kim, Y. K. Kim, J. W. Koo, C. Y. Park, The Reliability and Validity of the Negative Acts Questionnaire-Revised (NAQ-R) for Nurses for the Assessment of Workplace Bullying, Annals of Occupational and Environmental Medicine, (2010) Vol.22, No.2, pp.129-139. UCI : G704-000627.2010.22.2.005 
[40] C. G. Kim, Spirituality and stress in mental health of social workers, Journal of Hospice and Palliative Care, (2013), Vol.16, No.4, pp.253-263. UCI : G704-SER000009021.2013.16.4.005

[41] H. C. Ryou, J. O. Kong, H. G. Lee, S. J. Lee, J. C. Song, S. H. Chu, Y. H. Jung The Comparison of Job Stress Factors, Psychosocial Stress and Their Association between Research and Manufacturing Workers in an Automobile Research and Developing Company, Annals of Occupational and Environmental Medicine, (2009), Vol.21, No.4. pp.337-345. DOI: 10.35371/kjoem.2009.21.4.337

[42] Y. H. Kim, Preference Analysis of Forest Therapy Program according to the Stress Level, Korean Journal of Environment and Ecology, (2016), Vol.30, No.3. pp.434-442. DOI: 10.13047/KJEE.2016.30.3.434

[43] N. H. Cha, M. J. Wang, J. A. Kim, K. N. Lee, Difference of Physical Symptoms, PWI and JCQ according to Sasang Constitutions for Industrial Workers, Journal of Korean Academy of Community Health Nursing, (2005), Vol.16, No.4. pp.508-516.

[44] K. H. Kim, J. W. Kim, S. H. Kim, Influences of Job Stressors on Psychosocial Well-being, Fatigue and Sleep Sufficiency among Firefighters, Annals of Occupational and Environmental Medicine, (2006), Vol.18, No.3, pp.232-245. DOI: 10.35371/kjoem.2006.18.3.232

[45] Y. S. Shin, Y. J. Lee, J. O. Ham, E. C. Jang, C. H. Park, M. S. Kang, S. K. Park, A Study of Psychosocial Stress of Residents Near Asbestos Mines, Annals of Occupational and Environmental Medicine, (2012), Vol.24, No.4, pp.375-383. UCI : G704-000627.2012.24.4.003

[46] M. A. Han, S. Y. Ryu, J. Park, M. G. Kang, J. K. Park, K. S. Kim, Health-related Quality of Life Assessment by the EuroQol-5D in Some Rural Adults, Journal of Preventive Medicine and Public Health, (2008), Vol.41, No.3, pp.173-180. UCI : G704-000038.2008.41.3.001

[47] J. Y. Jo, J. H. Jeong, S. Y. Lee, H. S. Kwun, S. H Urm, B. C. Yu, Influences of stress and fatigue on periodontal health indicators in patients with periodontal disease, Journal of Korean Society of Dental Hygiene, (2016), Vol.16, No.2. pp.225-231. DOI: 10.13065/jksdh.2016.16.02.225

[48] S. H. Kim, S. Y. Bae, A study on the convergent factors related to depression among some administrative staff in Generla hospital, Journal of Digital Convergence, (2018), Vol.16, No.6, pp.251-258. DOI: 10.14400/JDC.2018.16.6.251

[49] Y. J. Cho, G. H. Lee, Relationship between Exercise Frequency and Stress in Korean Postmenopausal Women, stress (KSSM), (2016), Vol.24, No.3, pp.161-166. DOI : 10.17547/kjsr.2016.24.3.161 